\title{
Cost-benefit analysis of influenza vaccination in a public healthcare unit
}

\author{
Giorgio L Colombo' \\ Antonio Ferro ${ }^{2}$ \\ Marta Vinci ${ }^{1}$ \\ Maria Zordan² \\ Giulio Serra'
}

'S.A.V.E. Studi Analisi Valutazioni Economiche, Milano, Italia; ${ }^{2}$ Unità Locale Socio Sanitaria ULSS $n^{\circ} 17$, Regione Veneto, Italia
Correspondence: Giorgio L Colombo S.A.V.E. via Previati, 74, 20149 Milano, Italia

Tel +3902485I 9230

$\mathrm{Fax}+3902485 \mid 9231$

Email giorgio.colombo@savestudi.it
Objective: Estimate the costs and benefits of influenza vaccination in a group of employees of an Italian District Health Authority, Unità Locale Socio Sanitaria (ULSS), to define a scheme of an economic evaluation to be used for other vaccination strategies.

Design: In an observational study conducted from December 2002 to April 2003, 107 ULSS employees, voluntarily vaccinated, were compared with 107 nonvaccinated ULSS employees matched for age, sex, and job category. The outcome of cost-benefit analysis was evaluated by checking personnel department records about absences from work and their causes, including influenza. Costs and benefits of the influenza vaccination from the ULSS point of view were calculated.

Results: The influenza vaccination strategy reduced absences from work by $23 \%$ and decreased the loss of working days by $30 \%$ and related cost. This difference is not significative. The ratio vaccination benefits/cost was $€ 4.2$. The advantage of vaccination is confirmed by sensitivity analysis performed on the mean cost of a working day, which showed that the benefit-cost ratio ranged from $€ 4.5$ to $€ 11.7$.

Conclusions: The results suggest that the influenza vaccination strategy in our sample of people was cost-saving. The economic evaluation used in this study could also be used for other vaccination strategies and in other settings.

Keywords: economic evaluation, influenza vaccination strategy, observational study

\section{Introduction}

Influenza is a substantial epidemiological problem because of its ubiquity and contagiousness, the antigenic variability of its viruses and its possible serious complications. As an infectious illness, it is the third cause of death in the advanced economy countries, preceded only by HIV and tuberculosis (Bridges et al 2003). Because of the high mortality and morbidity rates (Landi et al 2003) in high-risk populations, its economic burden for society can be heavy.

Anti-influenza prophylaxis as long been widely suggested for risk categories such as people older than 64 years (Nichol and Goodman 1999; Gasparini et al 2002; Allsup et al 2003). At present, the effectiveness of flu prevention is normally evaluated on people of all ages who want both to avoid the disease, and to help in break the chain of infection, achieving in this way substantial reductions in morbidity (Gallo et al 2002; Rychlik et al 2003; Turner at al 2003; Principi and Esposito 2004).

Several studies have evaluated the economic burden of influenza in target populations: evidence from a review of influenza-related costs is the extent of indirect cost (loss of production) in proportion to the total cost of the illness, accounting for 70\%-90\% of influenza-related costs (Levy 1996; Kumpulainen and Makela 1997; Keech et al 1998; Postma et al 1999; Gasparini et al 2000; Nichol et al 2003). 
These assumptions are confirmed by the growing interest in economic evaluation of prevention strategies for the healthy working population (Nichol et al 1995; Postma et al 2002; Akazawa et al 2003). In this target population, the effect of vaccination is particularly important because it reduces the number of working days lost due to influenza and, from society's perspective, can lower the costs of loss of production that may be considered an economic benefit of the vaccination itself.

The Italian Health Ministry (Ministero della Salute 2003) advised that, with the aim of reducing morbidity of influenza and its complications, district public health structures must offer influenza vaccination to: people aged 65 years or older; children or adults with chronic respiratory, cardiovascular, uropoietic diseases, hemopoietic organ diseases, diabetes or other metabolic diseases, intestinal diseases, cystic fibrosis, HIV or other immune system diseases; people undergoing surgery; people working in public offices of high public interest; people working as nursing staff for highrisk patients, or their relatives; rheumatic children with pathologies requiring prolonged treatment with acetylsalicylic acid and running the risk of Reye's syndrome.

The aim of this study was to estimate the cost and benefits of a preventive influenza vaccination campaign in the employees of an Italian district healthcare unit, Unità Locale Socio Sanitaria ${ }^{\circ} 17$ (ULSS), from the employer's point of view, in order to define a cost-benefit analysis scheme to be used for other strategies of vaccination and in other settings. Two cohorts of employees were analysed (vaccinated and not vaccinated) calculating the losses of production due to influenza and all the total costs related to the vaccination.

\section{Methods}

In this observational study, conducted from December 2002 to April 2003, 107 employees who voluntarily received the vaccination were compared with 107 nonvaccinated employees matched for age, sex and job category, working in the same healthcare unit $(10.9 \%$ of the total staff of ULSS). In order to assess absences related to influenza-like illness (ILI) according to the WHO definition of influenza, employees were contacted by telephone at the end of the epidemic period.

To select the observation period, we analysed the incidence of flu per age group during the 2002/2003 epidemic season (Figure 1). In that season, according to the Ministry of Health epidemiological observatory (Ministero della Salute 2003), ILI patterns differed from the previous three seasons: the incidence was low up till the last weeks of 2002 and started rising in the last week (like during 20002001, but later than during 1999-2000 and 2001-2002). From available data, it was decided only to consider cases arising from 1 December 2002 to 15 April 2003.

\section{Cost analysis}

Economic evaluation of the vaccination program was performed from the perspective of the employer, focusing on the direct vaccination program costs, including the cost of vaccines, materials, and cost of administration; indirect

Figure I Season 2002-2003: incidence (/ 10000$)$ of ILI by age group.

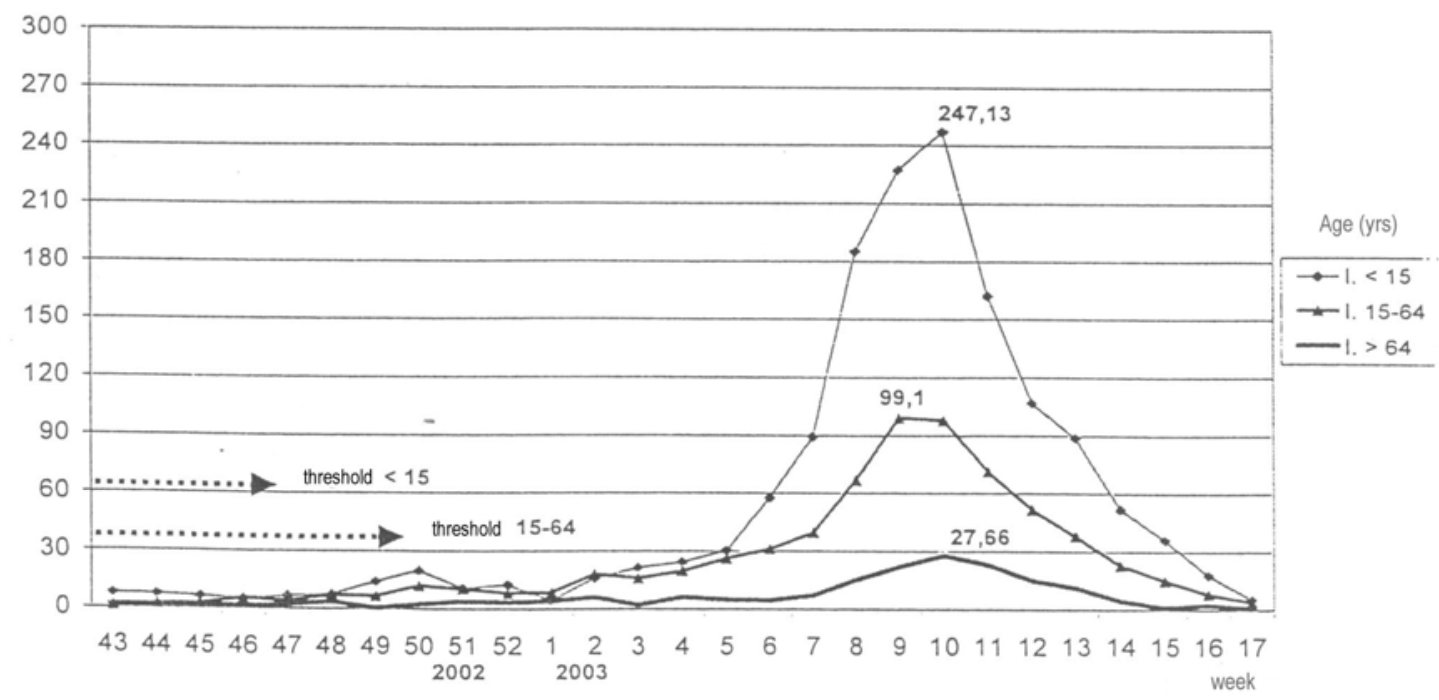

Abbreviations: ILI: influenza-like illness. 
costs of the vaccination program, including time for the employees to get the vaccine, sick leave, with or without temporary replacement of the employee (Table 1). The cost of these outcomes to the employer were estimated by considering salaries as well as the loss of income caused by the employee's absence or illness.

The economic evaluation was done from the ULSS perspective. Cost of vaccination was established considering:

- Purchase price $€ 4.774$ (vaccine used: split, AventisPasteur, source ULSS n 17 );

- Physician's time to administer vaccines: 5 minutes, based on the physician annual gross salary (eg, the cost to ULSS n 17 per employee);

- Nurse's time to assist the physician: 5 minutes, based on the nurse's annual gross salary;

- Time spent by employees to receive vaccine: 15 minutes, using the annual gross salary of each employee;

- Costs of preparation and executing the vaccine administration were estimated as a lump-sum amounting to $€ 0.103$ per patient.

The net economic benefit (CS) of the vaccination program was calculated using the following formula: $\mathrm{CS}=$ (cost of ILI in nonvaccinated employees) - (cost of ILI in vaccinated employees + cost of vaccination program).

Benefits of vaccinations were estimated as the reduction of production losses according to the Human Capital Method (Freund and Dittus 1992; Sloan 1995). The use of healthcare program can be viewed as an investment in a person's human capital. In measuring the return on this investment, the value of the healthy time produced can be quantified in terms of the person's renewed or increased production in the marketplace.
To assess the value of one lost working day, we used the mean annual labour cost to the ULSS $n^{\circ} 17$ for each job category. This value was obtained by adding the gross wage to fiscal drag (about $28 \%$ of gross wage) and IRAP (Imposta Regionale sulle Attività Produttive), a regional tax corresponding to $8.5 \%$ of gross wage) and dividing it by 220 working days (average working days per year in Italy).

As the analysis was done from the employers' perspective, costs sustained by sick employees for drugs, tests, physician visits, and hospitalizations were not considered. Sensitivity analysis was done on the labour cost: three scenarios were envisaged, valuing all absences with the same cost (in the vaccinated cohort and the control one) using minimum, base, and maximum labour costs.

\section{Cost-effectiveness analysis}

The reduction of the incidence of influenza among employees was considered in analyzing data collected at follow-up. Being the two cohorts of the same size the effectiveness of vaccination was calculated using the formula:

(Sick employees among nonvaccinated - sick employees among vaccinated) $\times 100$ Sick employees among nonvaccinated

or from the reduction in the number of working days lost.

\section{Statistics}

The control cohort was extracted from the total of nonvaccinated employees according to a random stratified sampling procedure. Three strata were selected: sex, age (under or over 40 years) and job category. The aim was to obtain homogeneous samples according to income, ie according to unit's labour cost. The association between two

Table I Source and calculation for economic data

\begin{tabular}{|c|c|}
\hline Economic items & Economic evaluation \\
\hline \multicolumn{2}{|l|}{ Vaccination program: direct costs } \\
\hline Cost of vaccines and materials & Purchasing prices \\
\hline Cost of administration by nurse & Time $\mathrm{x}$ hourly labor costs \\
\hline \multicolumn{2}{|l|}{ Vaccination program: indirect costs } \\
\hline Cost of average time lost by employees for vaccination & Time $(15 \mathrm{~min}) \times$ minute cost of individual labor \\
\hline Cost of working days lost due to adverse events & Time $x$ day cost of individual labor \\
\hline \multicolumn{2}{|l|}{ Vaccination program: indirect benefits } \\
\hline Cost of sick leaves due to ILI avoided & Number of days $x$ day cost of individual labor \\
\hline \multicolumn{2}{|l|}{ ILI: indirect costs } \\
\hline Cost of sick leaves & Number of days $x$ day cost of individual labor \\
\hline
\end{tabular}

Abbreviations: ILI, influenza-like illness. 
quantitative variables was estimated by using the Pearson linear correlation coefficient or Spearman when Pearson's coefficient was not applicable. Pearson's chi-square test was used to verify homogeneity between cohorts of stratum variables; t-test for independent samples was used to compare age, logarithmic transformation of average daily cost (costs were transformed to obtain a normal distribution), and observed outcomes.

\section{Results}

The total number of people who declared to have had the flu is 55: 24 (22.42\%) of the vaccinated cohort and 31 (28.97 $\%$ ) of the nonvaccinated cohort. The total working days lost due to flu have been 161 for the first and 231 for the second one. This means that also if this difference (30.3\%) is not significant $(\mathrm{p}=0.329)$ it is relevant.

The sampling methods gave two homogeneous cohorts, summarized in Table 2. The mean age was similar in the vaccinated and nonvaccinated groups. Among vaccinated employees, $32 \%$ were males while in nonvaccinated males were about 25\% (not significant, $\mathrm{p}=0.289$ ). Mean labour cost of the two cohorts was close to $€ 200$.

Total cost of vaccination was about $€ 1866$, for an average of $€ 17.45$ per patient (Table 3 ). Administration of the vaccines took about ten hours of the medical staff (physicians and nurses were all ULSS n ${ }^{\circ} 17$ employees) for a total cost of $€ 506.65$ for the doctor and $€ 182.44$ for the nurse.

Time spent by employees to receive vaccine was valued, using the mean hourly cost per job category of the enrolled employees, at $€ 656.04$ (35\% of the total cost) - sources

Table 2 Population characteristics

\begin{tabular}{|c|c|c|c|}
\hline & $\begin{array}{l}\text { Vaccinated } \\
n=107\end{array}$ & $\begin{array}{l}\text { Non- } \\
\text { vaccinated } \\
n=107\end{array}$ & p value \\
\hline Age (mean $\pm S D)$ & 44.3 & 43.2 & 0.376 \\
\hline Age (min-max) & $24-62$ & $26-60$ & \\
\hline Males & $31.8 \%$ & $25.2 \%$ & 0.289 \\
\hline Managers & $16.8 \%$ & $18.7 \%$ & 0.935 \\
\hline Employees & $19.6 \%$ & $19.6 \%$ & 0.935 \\
\hline Manual workers & $63.6 \%$ & $61.7 \%$ & 0.935 \\
\hline $\begin{array}{l}\text { Mean cost of one } \\
\text { working day }(€)\end{array}$ & 196.20 & 202.36 & 0.741 \\
\hline
\end{tabular}

Abbreviations: max, maximum; min, minimum; SD, standard deviation.
Table 3 Cost of anti-influenza vaccination $(n=107)$

\begin{tabular}{lll}
\hline Cost items & Total & $\%$ \\
\hline Vaccine $(€ 4.774 \times 107 \mathrm{pts})$ & 510.82 & $27.4 \%$ \\
Physician $(€ 4.735 \times 107 \mathrm{pts})$ & 506.65 & $27.1 \%$ \\
Nurse $(€ \mathrm{I} .705 \times 107 \mathrm{pz})$ & 182.44 & $9.8 \%$ \\
Working time lost & 656.04 & $35.1 \%$ \\
Preparation, carrying out and waste & & \\
discharging & 11.05 & $0.6 \%$ \\
\hline Total vaccination costs & $€ 1866.99$ & $100 \%$ \\
\hline
\end{tabular}

ULSS $n^{\circ} 17$. The direct cost of the vaccine is $27 \%$ of the total cost.

These data confirm the importance of indirect costs (loss of production) amounting to than $70 \%$ of the total cost of the vaccination program.

Costs for preparation, carrying out the vaccination and waste disposal were evaluated in 11.05. Stocking cost was not considered because there was already a refrigerator in the physicians office; the cost of the vaccination campaign among employees was not considered either, because it was irrelevant.

Table 4 shows that 24 vaccinated employees were absent for influenza, totalling 161 working days lost, while 31 nonvaccinated people lost 231 working days. The vaccinated cohort was absent 1.5 days on average and the nonvaccinated cohort 2.2 days, for a reduction of $32 \%$ (ns).

Using the mean cost of a working day per job category to measure the economic impact of the absences, the total cost was $€ 39250$ for the nonvaccinated cohort and $€ 31840$ for the vaccinated one. The mean cost of each working day lost by nonvaccinated employees was lower than the vaccinated group.

The vaccination appeared to reduce days of absence from work, but the differences between the groups were not statistical significant.

Vaccination cost (€1866.99) must be added to the cost of production lost to get the total cost of vaccinated employees, ie $€ 33347$, saving about $€ 55$ per employee for a total of $€ 5900$ (Table 5).

The cost-benefit ratio for this vaccination program is $€ 4.2$, meaning $€ 1$ invested returns $€ 4$ saved through less absenteeism from work.

Results show the vaccine reduced the incidence of influenza with about $23 \%$ fewer working absences due to influenza and a shorter duration of the absences (6.7 days for vaccinated employees and 7.5 for not vaccinated).

Comparing results between cohorts, we noticed that absent employees in the nonvaccinated group had a lower 
Table 4 Number of absent employees, lost working days and total costs due to influenza-related absences

\begin{tabular}{|c|c|c|c|c|c|}
\hline & $\begin{array}{l}\text { Vaccinated } \\
\text { (a) }\end{array}$ & $\begin{array}{l}\text { Non- } \\
\text { vaccinated } \\
\text { (b) }\end{array}$ & $\begin{array}{l}\text { Differences } \\
\text { (b-a) }\end{array}$ & $\begin{array}{l}\text { Differences \% } \\
(\mathbf{b}-\mathbf{a}) / \mathbf{b} \times 100\end{array}$ & p value \\
\hline Employees (n) & 107 & 107 & - & - & - \\
\hline Employees absent (n) & 24 & 31 & 7.00 & $22.6 \%$ & 0.317 \\
\hline Working days lost (n) & 161 & 231 & 70.00 & $30.3 \%$ & 0.329 \\
\hline Mean duration of absence per absent employee (days) & 6.7 & 7.5 & 0.74 & $10.0 \%$ & - \\
\hline Mean duration of absence per employee (days) & $\mathrm{I} .5$ & 2.2 & 0.65 & $30.3 \%$ & - \\
\hline Total cost of the absences $€$ & $31,479.55$ & $39,250.00$ & $7,770.45$ & $19.8 \%$ & 0.444 \\
\hline Mean daily cost of the absence $€$ & 195.53 & 169.91 & $(25.6 I)$ & $-15.1 \%$ & 0.922 \\
\hline
\end{tabular}

Table 5 Results (mean values $n=107$ )

\begin{tabular}{|c|c|c|c|c|c|c|}
\hline & \multicolumn{3}{|l|}{ Total } & \multicolumn{3}{|c|}{ Per employee } \\
\hline & $\begin{array}{l}\text { Vaccinated } \\
\text { (a) }\end{array}$ & $\begin{array}{l}\text { Nonvaccinated } \\
\text { (b) }\end{array}$ & $\begin{array}{l}\text { Difference } \\
\text { (b-a) }\end{array}$ & $\begin{array}{l}\text { Vaccinated } \\
\text { (a) }\end{array}$ & $\begin{array}{l}\text { Nonvaccinated } \\
\text { (b) }\end{array}$ & $\begin{array}{l}\text { Difference } \\
(b-a)\end{array}$ \\
\hline Vaccination costs $(€)$ & $1,866.99$ & - & $-1,866.99$ & 17.45 & - & -17.45 \\
\hline Absence costs $(€)$ & $31,479.55$ & $39,250.00$ & $7,770.45$ & 294.20 & 366.82 & 72.62 \\
\hline Total cost $(€)$ & $33,346.53$ & $39,250.00$ & $5,903.47$ & 311.65 & 366.82 & 55.17 \\
\hline
\end{tabular}

mean daily cost than the vaccinated group (€169.91 vs $€ 195.53)$.

Among the costs, purchase of the vaccine was only $27 \%$ of the total cost and time lost by employees was the component weighing most in the vaccination program's costs (about 35\%).

\section{Sensitivity analysis}

A univariate sensitivity analysis was performed. This analysis was done on the average daily cost of labour, establishing a single value for each employee and testing how the cost-benefit ratio changes. Analysis was conducted assuming a minimum of $€ 100$, an average of $€ 180$ and a maximum of $€ 460$, corresponding to annual costs of $€ 22000, € 40000$ and $€ 100000$. Results are summarized in Table 6: the cost-benefit ratio rises from $€ 4.5$ to $€ 11.7$ from the minimum to the maximum scenario. The higher cost of an absent person salary determines an increase of the benefit of the vaccination program (from $€ 65.42$ to $€ 300.93$ ).

\section{Discussion}

During the peak of incidence, flu determines a high number of working absence with a reduction of productivity of ill people (Nichol et al 1995; Campbell and Rumley 1997; Keech et al 1998; Nicholson 1998; Olsen et al 1998; Wilde et al 1999). This reduction of productivity is not caused by illness in high risk people, but by illness in normally healthy adult people of working age. About $50 \%$ of working absences is caused by flu in manual workers aged between 25 and 44 years (Gardener and Schaffner 1993; Campbell and Rumley 1997). This study evaluated costs and benefits, from a district public healthcare unit's (ULSS $n^{\circ} 17$ ) perspective, of an influenza vaccination strategy among the unit's employees. Vaccination costs, such as purchase price, time spent by the physician, nurse and employees for vaccination, preparation, carrying out and disposal costs, and benefits (less absenteeism and lost productivity according to Human Capital Methods [Freund and Dittus 1992; Sloan 1995]) were calculated in each cohort.

The research findings emphasize that the influenza vaccination brings benefits: there is a reduction of working day absence and the duration of absence. Such reduction therefore allows a contraction of indirect costs, which differ from 31479 of vaccinated employees to 39250 of the nonvaccinated group. Clearly, considering the direct costs of vaccination, this difference is reduced, but a net economical benefit of vaccination remains. This reduction is not statistically significant. Another important aspect to take into consideration is that costs for the cure of influenza have not been valued, including the possible hospitalization of critical cases, as only the expenses sustained by the ULSS have been considered, instead of the expenses sustained by the employees. 
Some Italian studies have assessed vaccination costs among working age people (Colombo et al 2001) and among the elderly (Gasparini et al 2003; Montomoli et al 2003) (Table 6). The cost of a vaccination program in a private company was $€ 16.27$, which is very close to that calculated in our study but with a different cost distribution. The vaccine cost more than in our study (67\% of total cost), probably because it was purchased by a private company, but the cost of time lost by employees to receive the vaccine was much lower ( $10 \%$ vs $35 \%$ in our study). The cost for the elderly ranged from $€ 10-15,45 \%$ of which is the cost of the vaccine.

This confirms that the cost of vaccine is only a small component of the total expenditure for a prevention campaign, while the cost of employees' time spent to receive or to administer vaccine is more substantial.

Net savings from anti-influenza vaccination is about $€ 55$ per employee (the total cost for 107 employees is more than $€ 5900)$; benefit, ie lower cost of fewer absences, is $€ 72.62$ per employee (the mean cost of absences of the nonvaccinated cohort was about $€ 367$ compared with $€ 294$ for vaccinated staff).

Cost-benefit analysis gave benefit-cost ratio of $€ 4.2$, ie $€ 1$ invested returns $€ 4.2$, measured by the cost of lower absenteeism, to the district healthcare unit. This study measured benefit as lower cost and fewer absences from work. If effectiveness is the same, ie same number of days lost in each cohort, the benefit could depend only on the cost of work (that is part of the cost of the vaccination program too because of the time spent to receive or administer the vaccine).

Sensitivity analysis showed that in the "minimum" scenarios, as the cost of a working day was the same in both cohorts, the cost-benefit ratio was higher than in the base case, in which the cost of the nonvaccinated group was lower.

Table 6 Sensitivity analysis

\begin{tabular}{ll}
\hline Cost and benefits & $\begin{array}{l}\text { Mean value per } \\
\text { employee }(\boldsymbol{\epsilon})\end{array}$ \\
\hline Cost of vaccination - min & 14.4 \\
Cost of vaccination - base & 16.9 \\
Cost of vaccination - max & 25.7 \\
Benefit - min & 65.4 \\
Benefit - base & 117.8 \\
Benefit - max & 300.9 \\
Benefit/cost ratio - min & 4.5 \\
Benefit/cost ratio - base & 7.0 \\
Benefit/cost ratio - max & 11.7 \\
\hline
\end{tabular}

It can be argued that the higher the labour cost, the greater the cost-benefit ratio of this influenza vaccination program, assuming the same level of effectiveness of the vaccine. In this study benefit from less productivity lost ranged from $€ 65$ to $€ 300$, depending on the mean salary of each vaccinated employee (from $€ 22000$ to $€ 100000$ yearly).

The Human Capital Method approach might overestimate indirect costs. The friction cost method (Koopmanschap et al 1995; Johannesson and Karlsson 1997; Koopmanschap and Rutten 1996a, 1998b) considers that when an employee is absent, not all the production will be lost because the absence is compensated by another employee or when the employee comes back to work. Introducing some compensation mechanisms to estimate production lost is a good way to evaluate absences of high job categories such as managers because it can be assumed that time lost due to illness will in fact be made up by the employee himself, avoiding any real loss of production as assumed by the Human Capital Method. The friction cost method usually reduces the evaluation of the cost of absenteeism, so in our study the benefit from vaccination could be overestimated.

This analysis adopted the ULSS $n^{\circ} 17$ perspective, so it did not consider the costs of treating patients because they are sustained by patient himself or by the SSN (Sistema Sanitario Nazionale - National Health Service). This means the results are conservative because of the benefit from reduced healthcare consumption to treat influenza and its complications due to the lower incidence of illness in the vaccinated cohort.

In other countries, many studies on costs and benefits of the annual of influenza vaccination programmes demonstrated the economical benefit of vaccination to the employer. A review of 11 health economics studies carried out between year 1979 and 2000 pointed out that 8 studies showed a clear benefit of the vaccination to the employees (Postma et al 2002).

Failure to show any benefit was linked to high vaccination costs, low incidence rate of influenza, or the short duration of sick leave. In the reviewed studies where cost benefits were found, they mostly resulted from indirect cost savings such as losses arising from absenteeism or low levels of production (Postma et al 2002). In fact, such indirect costs are the most important considerations for the benefits of such vaccination programs (Postma et al 2002; Akazawa et al 2003). Other health economic analyses have shown benefits of vaccination programs where influenza rate among the workforce are as low as $2 \%$ and that 
Table 7 Vaccination costs in other Italian studies $(€)$

\begin{tabular}{|c|c|c|c|c|c|c|c|c|c|c|}
\hline \multirow[t]{2}{*}{ Study } & \multicolumn{2}{|c|}{$\begin{array}{l}\text { ESTE } \\
(2002-2003)\end{array}$} & \multicolumn{2}{|c|}{$\begin{array}{l}\text { ENI } \\
(2000-200 I)^{25}\end{array}$} & \multicolumn{2}{|c|}{$\begin{array}{l}\text { Liguria } \\
(2000-2001)^{26}\end{array}$} & \multicolumn{2}{|c|}{$\begin{array}{l}\text { SIENA } \\
(1999-2000)^{27}\end{array}$} & \multicolumn{2}{|c|}{$\begin{array}{l}\text { SIENA } \\
(2000-2001)^{27}\end{array}$} \\
\hline & $\begin{array}{l}\text { Mean } \\
\text { value } \\
\text { per }\end{array}$ & & $\begin{array}{l}\text { Mean } \\
\text { value } \\
\text { per }\end{array}$ & & $\begin{array}{l}\text { Mean } \\
\text { value } \\
\text { per }\end{array}$ & & $\begin{array}{l}\text { Mean } \\
\text { value } \\
\text { per }\end{array}$ & & $\begin{array}{l}\text { Mean } \\
\text { value } \\
\text { per }\end{array}$ & \\
\hline Use of resources & employee & $\%$ & employee & $\%$ & employee & $\%$ & employee & $\%$ & employee & $\%$ \\
\hline \multicolumn{11}{|l|}{ Vaccine } \\
\hline$(€ 4774 \times 107 \mathrm{pz})$ & 4.77 & $27.4 \%$ & 10.85 & $66.7 \%$ & 6.83 & $44.8 \%$ & 4.73 & $45.5 \%$ & 4.57 & $44.7 \%$ \\
\hline \multicolumn{11}{|l|}{ Physician } \\
\hline$(€ 4735 \times 107 \mathrm{pz})$ & 4.74 & $27.1 \%$ & 2.62 & $16.1 \%$ & 4.79 & $31.4 \%$ & - & - & - & - \\
\hline \multicolumn{11}{|l|}{ Nurse } \\
\hline$(€ \mid 705 \times 107 \mathrm{pz})$ & I.7I & $9.8 \%$ & 1.13 & $7.0 \%$ & - & - & - & - & - & - \\
\hline \multicolumn{11}{|l|}{ Cost of working } \\
\hline time lost (I5 $\min \times \mathrm{pz}$ ) & 6.13 & $35.1 \%$ & 1.57 & $9.7 \%$ & - & - & - & - & - & - \\
\hline Physician's incentives & - & - & - & - & 2.63 & $17.3 \%$ & 5.63 & $54.2 \%$ & 5.61 & $55.0 \%$ \\
\hline Adverse events & - & - & - & - & 0.17 & $1.1 \%$ & 0.03 & $0.3 \%$ & 0.03 & $0.3 \%$ \\
\hline Transport & - & - & - & - & 0.77 & $5.1 \%$ & - & - & - & - \\
\hline \multicolumn{11}{|l|}{ Preparation, carrying } \\
\hline \multicolumn{11}{|l|}{ out and waste } \\
\hline disposal & 0.10 & $0.6 \%$ & 0.10 & $0.6 \%$ & 0.05 & $0.4 \%$ & - & - & - & - \\
\hline Total vaccination cost & 17.45 & $100 \%$ & 16.27 & $100 \%$ & 15.25 & $100 \%$ & 10.39 & $100 \%$ & 10.20 & $100 \%$ \\
\hline
\end{tabular}

vaccination of the healthy working population aged 18 to 50 years against influenza in a variety of settings is costeffective during most influenza seasons (Das Gupta and Guest 2002; Lee et al 2002). These findings have been confirmed by double blind, randomized, placebo controlled studies performed on adult workers in good health (Nichol et al 1995; Demicheli et al 2000; Postma et al 2002). The American Center for Disease Control and Prevention showed that the benefit of vaccination of healthy people of age $\leq 65$ years, is optimized when a vaccine strain chosen that matches the strain responsible for disease outbreaks in that year. Elsewhere, economic modelling has been used to indicate the pricing of a novel, nasal delivery system for an influenza vaccine to enable programs using this system to break even financially (Nichol et al 2003).

The benefit of an influenza vaccination program does not end with the vaccinated person but extends to people who are not vaccinated because they are less likely be infected, with a further gain for the structure that promotes the vaccination program (herd immunization), and fewer new cases. When the number of vaccinated people increases, the number of people who become ill decrease and the possibility of getting infected also drops. This is called herd immunity (Warburton et al 1972; Webster 2000; Brisson and Edmunds 2003) in epidemiology and "positive externalities" (Berger and Szucs 1999; Birch et al 1999; Schnoor 2003) in economics and is hard to measure, but is surely a further effect of vaccination that could boost the benefits evaluated in observational studies like this.

\section{Disclosure}

This study was supported by a grant from Sanofi-PasteurMSD S.p.a., Roma. The authors declare no other potential conflicts of interest.

\section{References}

Akazawa M, Sindelar JL, Paltiel AD. 2003. Economic costs of influenzarelated work absenteeism. Value Health, 6:107-15.

Allsup S, Gosney M, Haycox A, et al. 2003. Cost-benefit evaluation of routine influenza immunisation in people 65-74 years of age. Health Technol Assess, 7:iii-x, 1-65.

Berger K, Szucs TD. 1999. Socioeconomic evaluation in medicine in Europe. Core economic concepts. Pharmacoeconomics, 16(Suppl 1):19-25.

Birch S, Gafni A, O'Brien B. 1999. Willingness to pay and the valuation of programmes for the prevention and control of influenza. Pharmacoeconomics, 16(Suppl 1):55-61.

Bridges CB, Harper SA, Fukuda K, et al; Advisory Committee on Immunization Practices. 2003. Prevention and control of influenza: recommendations of the Advisory Committee on Immunization Practices (ACIP). MMWR Recomm Rep, 52(RR-8):1-34; quiz CE14.

Brisson M, Edmunds WJ. 2003. Economic evaluation of vaccination programs: the impact of herd-immunity. Med Decis Making, 23:7682 .

Campbell DS, Rumley MH. 1997. Cost effectiveness of the influenza vaccine in a healthy working age population. J Occup Environ Med, 39:408-14. 
Colombo GL, Nicosia V, Lesma A, et al. 2001. Analisi costi-benefici di una strategia vaccinale antinfluenzale condotta presso una società del gruppo ENI (Snamprogetti). Pharmacoeconomics Italian Research Articles, 3:71-80.

Das Gupta R, Guest JF. 2002. A model to estimate the cost benefit of an occupational vaccination programme for influenza with Influvac ${ }^{\circledR}$ in the UK. Pharmacoeconomics, 20:475-84.

Demicheli V, Jefferson T, Rivetti D, et al. 2000. Prevention and early treatment of influenza in healthy adults. Vaccine, 18:957-1030.

Freund DA, Dittus RS. 1992. Principles of pharmacoeconomic analysis of drug therapy. Pharmacoeconomics, 1:20-32.

Gallo G, Ciofi degli Atti ML, Cerquetti M, et al. 2002. Impact of a regional Hib vaccination programme in Italy. Vaccine, 20:993-5.

Gardener P, Schaffner W. 1993. Immunisation in adults. $N$ Engl J Med, 338:1252-8

Gasparini R, Lucioni C, Lai P, et al. 2003. Valutazione benefici-costi della vaccinazione antinfluenzale negli anziani in Liguria. Pharmacoeconomics Italian Research Articles, 5(Suppl 1):23-30.

Gasparini R, Lucioni C, Lai P, et al. 2002. Cost-benefit evaluation of influenza vaccination in the elderly in the Italian region of Liguria. Vaccine, 20(Suppl 5):B50-4.

Gasparini R, Pozzi T, Bonanni P. 2000. Valutazione dei costi di un'epidemia influenzale nella popolazione lavorativa di Siena. Giornale di Farmacoeconomia, 1:3-9.

Johannesson M, Karlsson G. 1997. The friction cost method: a comment. $J$ Health Econ, 16:249-55.

Keech M, Scott AJ, Ryan PJ. 1998. The impact of influenza and influenzalike illness on productivity and healthcare resource utilization in a working population. Occup Med (Lond), 48:85-90.

Koopmanschap MA, Rutten FFH. 1996a. Indirect costs: the consequence of productivity loss or increased cost of production. Med Care, 34(Suppl):DS59-68.

Koopmanschap MA, Rutten FFH. 1996b. A practical guide for calculating indirect costs of disease. Pharmacoeconomics, 10:460-6.

Koopmanschap MA, Rutten FFH, van Ineveld BM, et al. 1995. The friction cost method for measuring indirect costs of disease. $J$ Health Econ, 14:171-89.

Kumpulainen V, Makela M. 1997. Influenza vaccination among healthy employees: a cost-benefit analysis. Scand J Infect Dis, 29:181-5.

Landi F, Onder G, Cesari M, et al. 2003. Effects of influenza vaccination on mortality among frail, community-living elderly patients: an observational study. Aging Clin Exp Res, 15:254-8.

Lee PY, Matchar DB, Dennis A, et al. 2002. Economic analysis of influenza vaccination and antiviral treatment for healthy working adults. Ann Intern Med, 137:225-31.
Levy E. 1996. French economic evaluations of influenza and influenza vaccination. Pharmacoeconomics, 9(Suppl 3):62-6.

Ministero della Salute. 2003. Prevenzione e controllo dell'influenza: raccomandazioni per la stagione 2003-2004. Ministero della Salute; Circolare n. 5 del 22 luglio.

Montomoli E, Pozzi T, Alfonsi V, et al. 2003. Valutazione benefici-costi della vaccinazione antinfluenzale negli anziani in due stagioni epidemiche a confronto nella provincia di Siena. Pharmacoeconomics Italian Research Articles, 5(Suppl 1):31-8.

Nichol KL, Goodman M. 1999. The health and economic benefits of influenza vaccination for healthy and at-risk persons aged 65 to 74 years. Pharmacoeconomics, 16(Suppl 1):63-71.

Nichol KL, Lind A, Margolis KL, et al. 1995. The effectiveness of vaccination against influenza in healthy working adults. $N$ Engl J Med, 333:889-93.

Nichol KL, Mallon KP, Mendelman PM. 2003. Cost benefit of influenza vaccination in healthy, working adults: an economic analysis based on the results of a clinical trial of trivalent live attenuated influenza virus vaccine. Vaccine, 21:2207-17.

Nicholson KG. 1998. Human influenza. In: Nicholson KG, Webster RG, Hay AJ, (eds). Textbook of Influenza. London: Blackwell Sci Ltd.

Olsen GW, Burris JM, Burlew MM, et al. 1998. Absenteeism among employees who participated in a workplace influenza immunization program. J Occup Environ Med, 40:311-16.

Postma MJ, Bos JM, Van Gennep M. 1999. Economic evaluation of influenza vaccination. Pharmacoeconomics, 16(Suppl 1):33-40.

Postma MJ, Jansema P, Marianne LL, et al. 2002. Pharmacoeconomics of influenza vaccination for healthy working adults. Drugs, 62:1015-24.

Principi N, Esposito S. 2004. Are we ready for universal influenza vaccination in paediatrics? Lancet Infect Dis, 4:75-83.

Rychlik R, Heinen-Kammerer T, Rusche H, et al. 2003. Cost-effectiveness of prophylaxis and treatment of influenza. Dtsch Med Wochenschr, 128:2267-70

Schnoor JL. 2003. Internalizing the externalities. Environ Sci Technol, 37:159A

Sloan FA. 1995. Valuing healthcare. Cambridge: Cambridge Univ Pr.

Turner D, Wailoo A, Nicholson K, et al. 2003. Systematic review and economic decision modelling for the prevention and treatment of influenza A and B. Health Technol Assess, 7:iii-iv, xi-xiii, 1-170.

Warburton MF, Jacobs DS, Langsford WA, et al. 1972. Herd immunity following subunit influenza vaccine administration. Med J Aust, 2:6770 .

Webster RG. 2000. Immunity to influenza in the elderly. Vaccine, 18:1686-9.

Wilde JA, McMillan JA, Serwint J, et al. 1999. Effectiveness of influenza vaccine in healthcare professionals. JAMA, 281:908-13. 